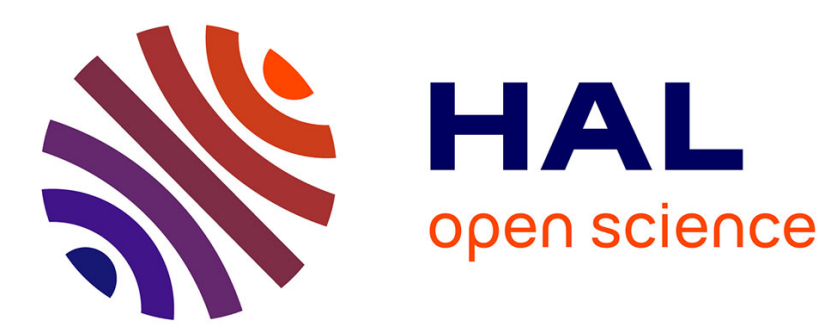

\title{
Enhancing Comfort of Occupants in Energy Buildings
}

Monalisa Pal, Amr Alzouhri Alyafi, Sanghamitra Bandyopadhyay, Stéphane

Ploix, Patrick Reignier

\section{To cite this version:}

Monalisa Pal, Amr Alzouhri Alyafi, Sanghamitra Bandyopadhyay, Stéphane Ploix, Patrick Reignier. Enhancing Comfort of Occupants in Energy Buildings. Operations Research and Optimization, pp.111, 2018. hal-01865292

\section{HAL Id: hal-01865292 https://hal.science/hal-01865292}

Submitted on 31 Aug 2018

HAL is a multi-disciplinary open access archive for the deposit and dissemination of scientific research documents, whether they are published or not. The documents may come from teaching and research institutions in France or abroad, or from public or private research centers.
L'archive ouverte pluridisciplinaire HAL, est destinée au dépôt et à la diffusion de documents scientifiques de niveau recherche, publiés ou non, émanant des établissements d'enseignement et de recherche français ou étrangers, des laboratoires publics ou privés. 


\title{
Enhancing Comfort of Occupants in Energy Buildings
}

\author{
Monalisa Pal ${ }^{1 \star}$, Amr Alzouhri Alyafi ${ }^{2,3}$, Sanghamitra Bandyopadhyay ${ }^{1}$, \\ Stéphane Ploix ${ }^{2}$, and Patrick Reignier ${ }^{4}$ \\ 1 Machine Intelligence Unit, Indian Statistical Institute, \\ 203 Barrackpore Trunk Road, Kolkata - 700108, India \\ 2 GSCOP Laboratory, Grenoble Institute of Technology, \\ 46, Avenue Felix Viallet, 38031 Grenoble, France \\ 3 LIG Laboratory, Grenoble Institute of Technology, \\ 46, Avenue Felix Viallet, 38031 Grenoble, France \\ 4 Univ. Grenoble Alpes, CNRS, INRIA, LIG \\ F-38000 Grenoble, France \\ monalisap90@gmail.com, amr.alzouhri-alyafi@imag.fr, \\ sanghami@gmail.com, stephane.ploix@grenoble-inp.fr, \\ patrick.reignier@inria.fr
}

\begin{abstract}
As buildings contribute significantly towards global energy consumption, it is essential that the occupants receive the best comfort without utilising further energy. This work treats building, environment and the occupants as a system, which presents the context and the occupants also provide their comfort criteria to a black box for yielding the a schedule of actions (opening/closing of doors/windows) for optimal comfort. The physical state of an office, situated in France, is recorded over a span of 100 days. This data is utilised by a physical model of the building to simulate the indoor ambience based on random sets of user actions from which an optimal schedule is obtained, representing equally best trade-off among minimal thermal and $\mathrm{CO}_{2}$ based air quality dissatisfaction. Results indicate that adopting the proposed schedule of user actions can efficiently enhance the occupants comfort.
\end{abstract}

Keywords: Differential Evolution, energy management, multi-objective optimization, Pareto-optimality, smart buildings

\section{Introduction}

Considering the ever-growing energy demand and the depletion of non-renewable energy resources, it is important to limit the energy usage in buildings which constitute roughly about $40 \%$ of the global energy supply. Thus, it is imperative to satisfy the demands of the building occupants without increasing the present rate of energy consumption in buildings. Occupant, on the other hand, being an

\footnotetext{
* corresponding author.
} 
integral part of the building system, can affect the indoor environmental condition through their actions. By intelligently utilising these actions, positive effects can be brought upon the indoor environment. Thus, guiding the occupant's actions, like opening and closing of doors and windows, for significant period of time, can help achieve better comfort in energy building at the same cost of energy consumption.

Attempts have been considered to meet the comfort demands of the occupants by improving building construction techniques and adding insulation to walls and ceilings. Building regulations also play an important role in the overall (both global and local) energy management. However, obtaining positive impacts of occupant's actions in the energy consumption can help to manage their own comfort. It is therefore important to assist the occupants with an optimal energy plan in order to explain that their expectations on comfort can be attained by themselves to some extent.

The approach used in this work considers an office, situated in Grenoble Institute of Technology, France, fitted with 27 sensors, for collection of data like temperature, solar illuminance, wind speed, humidity, moisture, $\mathrm{CO}_{2}$ concentration, etc., to construct the physical context. Also a physical model of the office is used which based on the physical context of outside environment and neighbouring corridors, and a random set of actions can simulate the indoor ambience. The indoor temperature and $\mathrm{CO}_{2}$ concentration are responsible for thermal and air quality dissatisfaction of the occupants. This work uses a multi-objective optimization algorithm viz. Differential Evolution to obtain the schedule of user actions that can lead to minimal thermal and air quality dissatisfaction. On presenting the occupants with this optimal schedule, they can compare it with their previous schedule and adopt the new schedule, after trial, if they find significant improvement of comfort.

Depending on the weather changes, the optimal schedule is variable. However, rarely, there are day to day changes in the outside temperatures and $\mathrm{CO}_{2}$ concentrations. Hence, learning from past day's environmental conditions and occupant's actions, the proposed optimal set of actions can be adopted for next day.

Rest of the paper is organized as follows. Section 2 describes the information flow to yield the schedule of actions corresponding to the trade-offs between minimal thermal and air-quality dissatisfactions. Section 3 discusses the results to assess the efficacy of the proposed approach. Section 4 presents the conclusion while directing towards future research.

\section{Experimental framework}

This work presents optimal schedules of actions (opening/ closing of doors/ windows) which the occupants can adopt to achieve better thermal and $\mathrm{CO}_{2}$ based air quality comfort at no extra energy expenditure. As the proposed scheme aims at improving occupant's comfort without increasing energy consumption, this can be considered as an energy management scheme. The general schema 


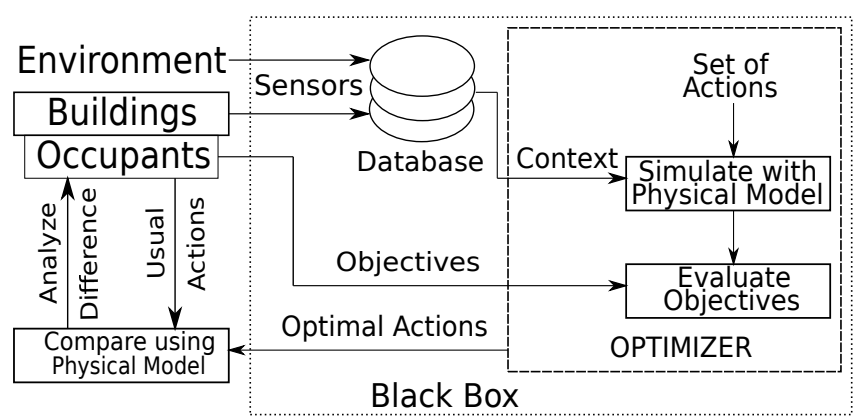

Fig. 1. General Schema of Energy Management in Smart Buildings.

of the work is shown in Fig. 1. In this section, the function of each of these modules is explained in details along with the overall interconnection of the modules to explain the information flow. It is to be mentioned that the environment, buildings and the occupants represent the smart building system where the environment and buildings contribute to the physical context/state, and the occupants, on the other hand, generate actions and provide their comfort criteria to a black box. Finally, the occupants compare their actions with the optimal actions generated by the black box in order to learn the scope of improvement in their comfort. As the internal operation of the optimizer is unknown to the occupant, it has been labeled as a black box.

\subsection{Building and Environment}

Through an array of sensors, the physical state of the outdoor, indoor and neighbouring zones are recorded. Here, physical state refers to temperature, $\mathrm{CO}_{2}$ concentration, humidity, etc. The inertia of these physical quantities from the outside environment and neighbouring zones like corridors, staircase, etc. influence the physical quantities inside the room of the occupant. Hourly samples of such quantities are recorded in the database for future reference. Here, as a testbed, an office room at Grenoble Institute of Technology, France, where four researchers work, are fitted with 27 sensors for recording the physical state/context and usual schedule of actions. This acts as the smart building system for the proposed work.

\subsection{Occupants}

Occupants are the integral part of the entire system. On one hand, they provide the optimization criteria like comfort, energy consumption, etc. for obtaining an optimal schedule of actions and on the other hand, their actions influence the system which in turn affects the optimization criteria. In absence of controllable HVAC (Heating, Ventilation and Air Conditioning) system, the only actions of the occupants which can influence the indoor ambient conditions (and hence, 
their comfort) are opening and closing of doors and windows. The occupants can compare the optimal schedules with their usual schedule and adopt the proposed schedules as per need. For example, if the difference in comfort is negligible the occupant might not prefer to change their schedule, whereas if the occupant observes significant improvement in comfort, the occupant is expected to adopt the proposed schedules of actions.

After the basic building block viz. the smart building system, and its purpose, has been explained, the next step is to obtain the optimal schedules of actions. The optimizer module, as explained next, helps in searching for best trade-offs among the objectives provided by occupants.

\subsection{Optimizer}

The role of the optimizer is to yield a few optimal schedules of actions. The essential specifications for the optimization module are as follows: the representation of the solution vector in order to decode the result, the optimization algorithm, the objectives and their relation to the solution vector, the stopping condition and the algorithmic parameters.

A solution of the optimization problem represents a set of actions. The allowed actions for the occupants are opening and closing of doors and windows. As the data are recorded in an office environment, the actions are noted over 12 working hours i.e. from $8 \mathrm{am}$ to $8 \mathrm{pm}$. Hence, the solution is represented by a 24-dimensional binary vector where the first 12 entries imply opening/closing (open $=1$, close $=0$ ) of windows and the later 12 entries are for opening/closing of doors for each of the 12 working hours, respectively.

Given the environmental context of the room, the primary objective of the work is to obtain various schedules, such that each of the schedules represent trade-offs among several conflicting objectives like minimizing thermal dissatisfaction, minimizing $\mathrm{CO}_{2}$ based air quality dissatisfaction, minimizing humidity based air quality dissatisfaction, minimizing energy consumption, etc. Due to the presence of multiple objectives, a multi-objective version of an optimization algorithm viz. Differential Evolution $[4,3]$ has been employed.

Assuming a physical context (indoor and outdoor environmental variables like $\mathrm{CO}_{2}$ concentration, temperature, etc.) and a set of actions (opening/closing of doors/windows) as inputs to the smart building system (outdoor environment and building with occupants), it outputs some effects (like thermal and air quality comfort). A physical model $[1,5]$ representing this system has been used which can simulate the effects corresponding to random sets of actions, in the same context as obtained from the database. These random sets of actions generate various sets of effects. Several best trade-offs among the effects (generating the Pareto-Front) are chosen. Then, the occupants can compare the schedule of actions corresponding to these trade-offs with their usual schedules to analyze the difference. Hence, evaluation of objectives is a two-step process. The first step uses the physical model of the office to evaluate indoor environmental variables depending on a true context and a randomly assumed schedule of actions. The model is represented by Eq. (1) and (2) where the variables 
are defined in Table 1. Some of these variables represent sensor measurements whereas the remaining ones are learned by repeated simulation of the physical model to match the office room. The second step evaluates effects (here, thermal and $\mathrm{CO}_{2}$ based air quality dissatisfaction) from the simulated indoor physical variables. These effects are shown in Eq. (4) and (5) which represent thermal and air quality dissatisfaction at the $i$-th hour, respectively. The objectives are formulated keeping in mind that the indoor temperature is preferred between $21^{\circ} \mathrm{C}$ to $23^{\circ} \mathrm{C}$ and the indoor $\mathrm{CO}_{2}$ concentration is preferred between $400 \mathrm{ppm}$ to $1500 \mathrm{ppm}$. The purpose of the optimizer is to optimize (minimize) the effects (dissatisfaction levels) as formulated by Eq. (3).

$$
\begin{aligned}
& T_{\text {in }}= \frac{R}{R_{i}} \tau+R\left(\frac{1}{R_{\text {out }}}+\frac{\zeta_{W}}{R_{W}}\right) T_{\text {out }}+R\left(\frac{1}{R_{n}}+\frac{\zeta_{D}}{R_{D}}\right) T_{n} \\
& V \frac{d C_{\text {in }}}{d t}=-\left(Q_{0}^{\text {out }}(t)+Q_{0}^{\text {cor }}(t)+\zeta_{W}(t) Q_{W}+\zeta_{D}(t) Q_{D}\right) C_{\text {in }} \\
&+\left(Q_{0}^{\text {out }}(t)+\zeta_{W}(t) Q_{W}\right) C_{\text {out }}+\left(Q_{0}^{\text {cor }}(t)+\zeta_{D}(t) Q_{D}\right) C_{\text {cor }} \\
&+S_{C O_{2}} \times n(t) \\
& \text { Minimize: } D(\text { actions })=\left[d_{1}\left(T_{\text {in }}\right), d_{2}\left(C_{\text {in }}\right)\right]=\left[\frac{\sum_{i=1}^{12} d_{1}^{i}}{12}, \frac{\sum_{i=1}^{12} d_{2}^{i}}{12}\right]
\end{aligned}
$$

where,

$$
\begin{aligned}
& d_{1}^{i}\left(T_{i n}\right)= \begin{cases}\frac{21-T_{i n}}{21-18} & \text { if } T_{i n}<21 \\
0 & \text { if } 21 \leq T_{i n} \leq 23 \\
\frac{T_{i n}-23}{26-23} & \text { if } T_{i n}>23\end{cases} \\
& d_{2}^{i}\left(C_{i n}\right)= \begin{cases}0 & \text { if } C_{i n} \leq 400 \\
\frac{C_{i n}-400}{1500-400} & \text { if } C_{i n}>400\end{cases} \\
& \text { actions }=\left[\zeta_{W}^{1}, \zeta_{W}^{2}, \cdots, \zeta_{W}^{12}, \zeta_{D}^{1}, \zeta_{D}^{2}, \cdots, \zeta_{D}^{12}\right]
\end{aligned}
$$

Like most evolutionary optimization algorithms, the multi-objective version of Differential Evolution is executed for a predetermined number of generations by which the optimization algorithm is expected to have converged. The description of various parameters and their values for which best results are obtained are noted in Table 1.

At the end of the optimization algorithm, a few optimal schedules of actions are generated. The user can choose among these schedules based on their preference among the multiple objectives of optimality by comparing their usual schedule with the chosen schedule.

\subsection{Comparing Schedule of Actions}

Based on any schedule of actions, the physical model can generate the corresponding indoor ambience. The indoor ambience based on the usual schedule of the occupant is in the available from the database. Occupants can compare the 
simulated ambience (what best could have happened) to their usual ambience (what had actually happened) and understand the difference in effects to gain better comfort.

After the description of the experimental setup, the next section discusses various results in order to validate the proposed approach.

Table 1. Algorithmic Parameters and their Values.

\begin{tabular}{|c|c|c|c|}
\hline Module & Parameters & Explanation & Values \\
\hline \multirow{12}{*}{$\begin{array}{l}\text { Physical } \\
\text { Model }\end{array}$} & $\zeta_{W}, \zeta_{D}$ & Status of window(W), door(D) & Open $=1$, Close $=0$ \\
\hline & $T_{\text {in }}, T_{n}, T_{\text {out }}$ & $\begin{array}{l}\text { Temperatures of indoor, } \\
\text { adjacent corridor, outdoor }\end{array}$ & From database \\
\hline & $R_{D}, R_{W}$ & $\begin{array}{l}\text { Thermal resistances of door(D), } \\
\text { window }(\mathrm{W})\end{array}$ & From database \\
\hline & $R_{i}, R_{n}, R_{\text {out }}$ & $\begin{array}{l}\text { Resistance of walls, adjacent } \\
\text { corridor, outdoor }\end{array}$ & From database \\
\hline & $R$ & Equivalent resistance & $\begin{array}{l}R_{i}\left\|R_{\text {out }}\right\| R_{n} \| \\
R_{W}\left(\text { when } \zeta_{W}=1\right) \| \\
R_{D}\left(\text { when } \zeta_{D}=1\right) \\
\end{array}$ \\
\hline & $\tau$ & $\begin{array}{l}\text { Thermal coefficient representing } \\
\text { building inertia }\end{array}$ & From database \\
\hline & $V$ & Volume of the room (office) & From database \\
\hline & $C_{\text {in }}, C_{\text {out }}, C_{\text {cor }}$ & $\begin{array}{l}\mathrm{CO}_{2} \text { concentrations indoor, } \\
\text { outdoor, in adjacent corridor }\end{array}$ & From database \\
\hline & $Q^{\text {out }}, Q^{\text {cor }}$ & Air speed outdoor, in corridor & From database \\
\hline & $Q_{W}, Q_{D}$ & $\begin{array}{l}\text { Air speed through window(W), } \\
\text { door(D) }\end{array}$ & From database \\
\hline & $\mathrm{S}_{\mathrm{CO}_{2}}$ & $\begin{array}{l}\text { Breath production of } \mathrm{CO}_{2} \\
\text { per occupant }\end{array}$ & From database \\
\hline & $n(t)$ & Number of occupants at time $t$ & From database \\
\hline \multirow{5}{*}{$\begin{array}{l}\text { Differential } \\
\text { Evolution } \\
\text { (Optimizer) }\end{array}$} & $N P$ & Population size & 20 \\
\hline & $G_{\max }$ & Maximum generations & 300 \\
\hline & $F$ & Scale Factor & $\begin{array}{l}\text { Randomly choosen } \\
\text { between } 0 \text { and } 2\end{array}$ \\
\hline & $C R$ & Crossover Rate & 0.8 \\
\hline & $r$ & $\begin{array}{l}\text { Reference point for ranking } \\
\text { and decision making }\end{array}$ & $\begin{array}{l}\text { Ideal point i.e. } \\
(0,0)\end{array}$ \\
\hline
\end{tabular}

\section{Result and discussion}

This section analyses the performance of the proposed approach using the various results. Dissatisfaction levels as obtained from various simulated schedules are shown in a scatter plot. From these, the set of Pareto-optimal schedules obtained using optimization techniques are marked. Next the variation of average 
indoor temperature and $\mathrm{CO}_{2}$ concentration, obtained from optimal schedules, are compared with usual schedules. Finally, the variation of net dissatisfaction resulting from the proposed optimal schedule is shown to validate the optimization performance. The experimental data is collected for 100 days (1st April, 2015 to 9th July, 2015) and the analysis is conducted in 10 groups of 10 days each as shown in Table 2.

Table 2. Groups of Experimental Data Recorded during Working Hours (8am to 8pm).

\begin{tabular}{l|l|c|c} 
Group & Period & $\begin{array}{c}\text { Mean Outdoor } \\
\text { Temperature }\left({ }^{\circ} \mathbf{C}\right)\end{array}$ & $\begin{array}{c}\text { Outdoor } \mathbf{C O}_{2} \\
\text { concentration (ppm) }\end{array}$ \\
\hline \hline 1 & April 1 to April 10, 2015 & 10.1528 & \\
2 & April 11 to April 20, 2015 & 17.8809 & \\
3 & April 21 to April 30, 2015 & 17.1548 & \\
4 & May 1 to May 10, 2015 & 20.7708 & 395 \\
5 & May 11 to May 20, 2015 & 20.1111 & \\
6 & May 21 to May 30, 2015 & 15.9167 & \\
7 & May 31 to June 9, 2015 & 24.8571 & \\
8 & June 10 to June 19, 2015 & 21.5119 & \\
9 & June 20 to June 29, 2015 & 23.5417 & \\
10 & June 30 to July 9, 2015 & 28.7812 & \\
\hline
\end{tabular}

\subsection{Pareto-front and optimal schedules}

A set of Pareto-optimal solutions is obtained for every working day in the experimental duration. Depending on the occupant's preference, any one of these schedules can be chosen as the preferred optimal schedules. Considering equal preference for both the objectives, the solution nearest to reference point (at the minima for thermal and air-quality dissatisfaction i.e. at $(0,0)$ ) is considered as the best schedule. The solution at the end of the Pareto-front are also analysed further for comparison because these represent the best schedules with respect to each objectives (minimal thermal or $\mathrm{CO}_{2}$ based air quality dissatisfaction), independently. Hence, occupant's usual schedule is compared with three other schedules: best schedule, schedule for optimal thermal comfort and schedule for optimal air quality comfort. Using the context from 16th April, 2015, the thermal versus air quality dissatisfaction corresponding to various simulated schedules is shown Fig. 2. It also shows the Pareto-front and the three optimal schedules of interest, along with the usual level of dissatisfaction.

\subsection{Comparison of physical variables for different schedules}

As there are very less day to day changes in environmental conditions, the average of physical variables of 10 days (working hours only) are considered for 


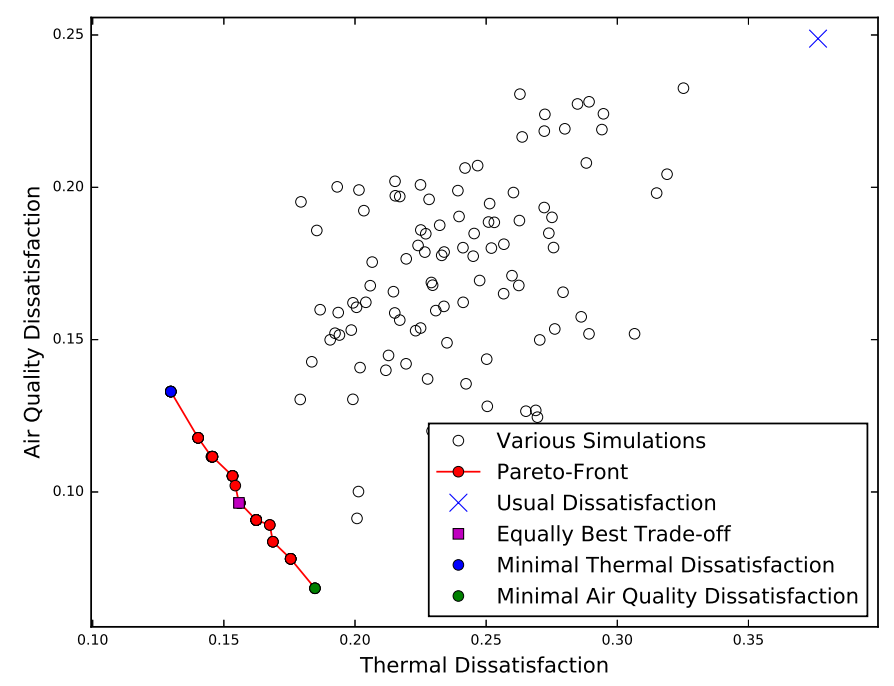

Fig. 2. Pareto-Front and Schedules of Interest.

comparison of the various schedules. Variations in indoor temperature and $\mathrm{CO}_{2}$ concentrations due to various schedules are presented in Fig. 3 and 4 for all the 10 groups of 10 days each as mentioned in Table 2. From the figures, it can be noticed that the difference between usual and proposed indoor physical variables (temperatures and $\mathrm{CO}_{2}$ concentrations) is more during earlier days of experiment. In summer (group 7 to 10), it is difficult to maintain the physical variables in preferred ranges just by varying the schedule of opening/closing of doors/windows. Hence, in extreme cases where outdoor physical variables (Table 2) are higher than preferred ranges, HVAC system is needed to regulate the indoor physical variables. It is also to be noted that the best schedule usually presents higher temperature than the schedules for optimal thermal comfort. Similar observation is also noted for indoor $\mathrm{CO}_{2}$ concentration. This is due to the fact the the best schedule presents a trade-off solution whereas the other proposed schedules are optimal with respect to one objective at a time.

\subsection{Performance analysis of optimization algorithm}

Optimization algorithm, in this case, presents a set of solutions, called the Pareto-optimal solution. The dissatisfaction values corresponding to these solutions create the Pareto-Front. To assess the convergence of the best schedule with respect to the ideal optimal solution, the city-block distance (sum of absolute difference) [2] between the corresponding dissatisfaction levels are measured. This distance represents the net dissatisfaction which is to be minimized. The parameters required for this performance metric viz. the reference point, is noted in Table 1. Box plots for the distribution of net dissatisfaction for the best sched- 


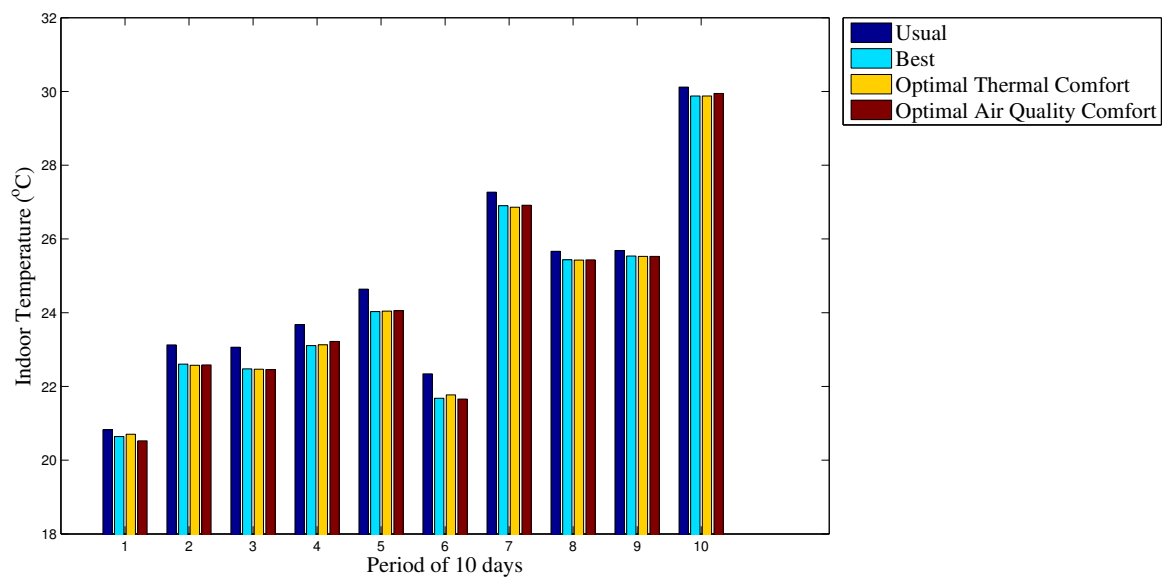

Fig. 3. Variation in Indoor Temperature Resulting from Different Schedules in the Experimental Duration.

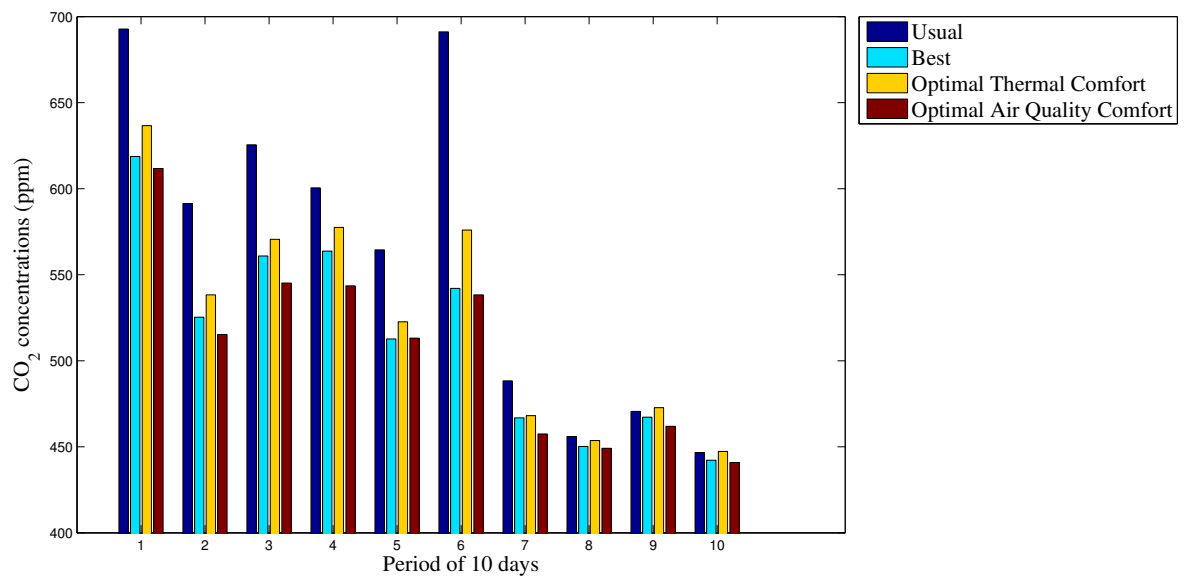

Fig. 4. Variation in Indoor $\mathrm{CO}_{2}$ Concentrations Resulting from Different Schedules in the Experimental Duration. 
ule of the Pareto-front is noted in Fig. 5 for all the 10 groups which shows that the median is close to 0 and the range of values is very less towards the earlier group and becomes higher for later groups. For a general idea of the range of dissatisfaction values, the theoretical variation of dissatisfaction are plotted against indoor temperature and indoor $\mathrm{CO}_{2}$ concentration in Fig. 5 which follows from Eq. (4) and (5). As noted from these plots, a combined dissatisfaction value around 2 or higher indicates that the indoor physical variables are not within preferred ranges. This implies that the proposed optimization approach is reproducible and efficient in yielding optimal schedules for this application during those period when HVAC system is not needed and thus, managing energy efficiently in the studied scenario.
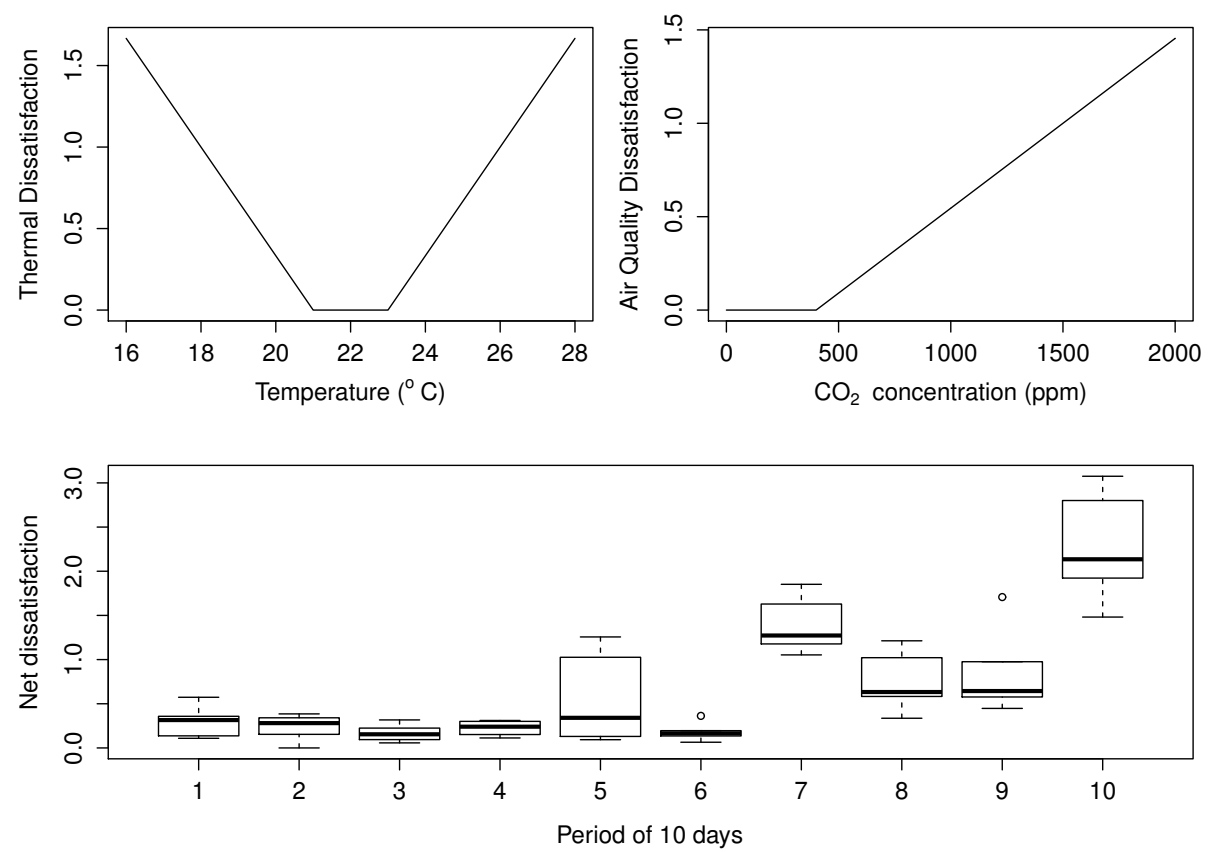

Fig. 5. Variation in Net Dissatisfaction for the Best Schedule in the Experimental Duration.

\section{Conclusion}

The objective of this work is to demonstrate an approach which considers the occupant's schedule of actions as the only controllable parameter of thermal and $\mathrm{CO}_{2}$ based air quality comfort and yields several schedules of actions which represent the best trade-offs between thermal and air quality dissatisfaction. 
Among the several schedules, the schedule corresponding to the equally best compromise of air quality and thermal comfort is analysed further. This optimal schedule can lead to efficient energy management. This work also addresses the need of HVAC system which arises when the environmental variables (here, temperature and $\mathrm{CO}_{2}$ concentration) are too high from the preferred values such that change in schedule of actions can negligibly influence the comfort level of the occupants.

However, just presenting the optimal schedule might not convince the occupants to change their schedule. In order to gain occupant's trust on the system, the effect of small changes in action and the internal working of the black box are to be explained in non-technical terms. This can lead to better comfort without depending on external devices like HVAC system. The authors are working on the explanations and adding more context to improve the parameterization of overall comfort. On the other hand, when several devices including HVAC system (if required) are operational, their energy consumption and environmental impact form other important effects to be considered along with the comfort of the occupants. This forms open area of research along this domain of energy management in smart buildings.

Acknowledgments. This study has been supported by the Indian side of the project sanctioned vide DST-INRIA/ 2015-02/ BIDEE/ 0978 by the Indo-French Centre for the Promotion of Advanced Research (CEFIPRA - IFCPAR).

This work benefits from the support of the INVOLVED ANR-14-CE22-002001 project (http://www . agence-nationale-recherche.fr/?Projet=ANR-14CE22-0020) of the French National Research Agency, ANR: Agence Nationale de la recherche, which aims at implementing new occupant interactive energy services, like MIRROR, WHAT-IF and SUGGEST, into a positive energy building constructed at Strasbourg in France by Elithis.

\section{References}

1. Amayri, M., Ploix, S., Bandyopadhyay, S.: Estimating occupancy in an office setting. In: Sustainable Human Building Ecosystems. pp. 72-80. Carnegie Mellon University, Pittsburgh, USA (2015)

2. De Souza, R.M., De Carvalho, F.d.A.: Clustering of interval data based on cityblock distances. Pattern Recognition Letters 25(3), 353-365 (2004)

3. Pal, M., Bandyopadhyay, S.: Many-objective feature selection for motor imagery eeg signals using differential evolution and support vector machine. In: Microelectronics, Computing and Communications (MicroCom), 2016 International Conference on. pp. 1-6. IEEE (2016)

4. Robič, T., Filipič, B.: Demo: Differential evolution for multiobjective optimization. In: Evolutionary multi-criterion optimization. pp. 520-533. Springer (2005)

5. Scanu, L., Bernaud, P.B., Ploix, S., Wurtz, E.: Methodologie pour la comparaison de structures de modeles simplifies. IBPSA, France (2016) 